\title{
EDUCAÇÃO PROFISSIONAL E MERCADO DE TRABALHO: UMA INVESTIGAÇÃO A PARTIR DAS/DOS JOVENS DO IFS
}

\section{Professional education and labour market: an investigation from young IFS}

Elza Ferreira Santos ${ }^{1}$

\section{Resumo}

O presente trabalho trata das expectativas que jovens estudantes brasileiros têm em relação ao mercado de trabalho. Para tanto, muitos jovens procuram as instituições federais de educação profissional. A pesquisa situa-se no Instituto Federal de Sergipe. Nela, por meio de grupos focais e de entrevistas colhemos depoimentos de alunos/as dos cursos técnicos Eletrônica, Eletrotécnica e Desenvolvimento de Sistemas. Deles, procuramos perceber, além de suas expectativas, como se dá a formação acadêmico-profissional, como se relacionam com os professores e com os colegas, como se veem homens e mulheres trabalhadores da indústria. A pesquisa está direcionada para a educação profissional, mercado de trabalho e relações de gênero. Sua base teórica fundamenta-se em Charlot,

1 Possui graduação em Licenciatura Letras Português pela Universidade Federal de Sergipe (1993), mestrado em Mestrado em Ciências da Educação pela Universidade Lusófona de Humanidades e Tecnologias (2006), doutorado em Educação pela Universidade Federal de Sergipe (2013) e doutorado em Educação pela Universidade Federal de Sergipe (2012). Atualmente é professora do Instituto Federal de Educação, Ciência e Tecnologia de Sergipe. Tem experiência na área de Educação, com ênfase em Estudo de Gênero, atuando principalmente nos seguintes temas: prática de ensino, gênero, professora, magistério e arte, psicanálise. E-mail: elzafesantos@gmail.com 
Demo, Hirata, Butler etc. As entrevistas e grupos focais foram estudados a partir da análise de discurso numa perspectiva foucaultiana. Os resultados apontam para uma necessária reflexão acerca das relações entre mercado de trabalho e educação profissional.

Palavras-chave: Mercado de trabalho, Educação Profissional e Gênero

\section{Abstract}

The present work deals with the expectations that young Brazilian students have in relation to the labor market. For this, many young people seek out professional education institutions. The survey is located at the Federal Institute of Sergipe. In this school, through focus groups and interviews we collected statements from technical courses students of the Electronics, Electrotechnics and Development Systems Courses. From these students, we tried to realize, besides their expectations, how the academic and professional training occurs, the way they get in touch with teachers and class mates, and how they see themselves as men and women working in the industry. The research is directed towards professional education, labor market and gender relations. Its theoretical basis is supported by Charlot, Demo, Hirata, Butler etc.. The interviews and focus groups were studied from the analysis of discourse in a Foucauldian perspective. The results point to a necessary discussion about the relationship between labor market and professional education.

Keywords: Job Market, Professional Education and Gender

O presente trabalho trata das expectativas que jovens estudantes brasileiros têm de ingressar no mercado de trabalho ou de obter melhor colocação profissional. Para tanto, muitos jovens procuram as instituições de educação profissional crentes de que após o curso estarão empregados dignamente. Entre as instituições de ensino mais procuradas estão as que pertencem à Rede Federal. Assim, essa comunicação volta-se para o mercado de trabalho, para a educação profissional e para as relações de gênero.

Do ponto de vista teórico, baseia-se nos estudos da sociologia da educação, especialmente, os voltados para a educação profissional e dos movimentos feministas, prioritariamente os que versam sobre gênero. Do ponto de vista empírico, situa-se no Instituto Federal de Sergipe (IFS). Seus alunos e alunas, por meio de grupos focais - GF -, concederam-nos registros do seu cotidiano pedagógico nos quais procuramos perceber a formação 
acadêmico-profissional, o relacionamento com os/as professores/as e com os/as colegas e seus perfis de trabalhadores/as da indústria. São alunos/as dos cursos técnicos de Eletrotécnica, de Eletrônica e de Desenvolvimento de Sistemas na modalidade Ensino Médio.

A pesquisa faz parte de um projeto desenvolvido no doutoramento em educação na Universidade Federal de Sergipe (UFS). Para melhor compreensão, dividimos a comunicação em dois momentos, a saber: uma parte conceitual em que apresentamos um entendimento acerca da educação profissional, outra parte prática em que apresentamos a "juventude sergipana", o IFS e seus alunos/as, enfim, uma breve exposição dos achados da pesquisa. Sobressaem-se, em ambas as partes, as relações de gênero.

\section{Educação Profissional e Gênero}

Considerando gênero como constructo histórico social (Scott, 1989) ou como performance (BUTLER, 2003) - “... parece complicado acudir al plano biológico para explicar las diferencias educativas entre los sexos" (WEINER, 2010 , p. 23) pois as diferenças em torno do sexo variam de acordo com cada cultura ou com cada circunstância e posição que se tenha de tomar na vida.

Existem hoje vários testes que avaliam o rendimento de alunos/as e, consequentemente, seus interesses pelas disciplinas, cursos e trabalhos. Nunca é demais assinalar, entretanto, que os resultados de tais testes devem considerar que associados ao gênero estão fatores como etnia, classe e outros de cunho mais subjetivo com o entorno familiar, o currículo oculto, o material escolar de leitura etc. que podem direcionar preferências por disciplinas, criar determinadas habilidades e, no futuro, determinar escolhas profissionais.

Diversas pesquisas assinalam que as meninas se dão bem em leitura, interpretação de texto, ao passo que os meninos nas disciplinas que envolvem cálculo. Na Alemanha, por exemplo, Häussler e Hoffman mostraram que entre os estudantes de 11 a 16 anos, as meninas se interessavam menos do que os meninos pelos estudos de física. Entre os garotos e garotas que se interessavam por ciências, foi possível também perceber que havia 
gostos diferentes: as meninas preferiam "la luz, el sonido y el calor" e os meninos preferiam "la mecânica, la electricidad y la radioactividad" (HÄUSSLER \& HOFFMAN,1997/1998 apud WEINER, 2010, p. 28). Esses resultados coincidiam com a pesquisa anterior que apontavam mulheres mais próximas de carreiras como medicina e orientação e os homens por carreiras relacionadas com a física. Isso acontece em diversos outros países da União Europeia (WEINER, 2010).

Nas escolas profissionais, verifica-se essa distinção de escolhas. Nos EUA, em 1985, Klein (1985, apud Burger, Abbott, Tobias, Koch, Vogt, Sosa, Bievenue, Carlito, \& Strawn, 2007, p. 255) constatou certa ausência das muIheres em determinadas disciplinas: as mulheres eram sub-representadas no campo da ciência, da engenharia e da tecnologia. Se partirmos para os dados nos cursos superiores, ver-se-á um indicativo similar aos dos estudos secundários. Guardadas as diferenças entre um grau e outro, uma vez que nos cursos superiores existem sujeitos amadurecidos do ponto de vista psicológico e acadêmico, os números denotam que tanto homens quanto mulheres não se livraram das experiências familiares e pedagógicas anteriores.

Nos EUA, também essa diferenciação na escolha de carreiras é notável. Um estudo realizado pelo The National Women's Law Center em 2005 referente à educação científica e técnica, com crianças entre 9 e 12 anos de idade revelou que: "females represent more than five out of six students enrolled in courses in traditionally female fields, but just 1 out of every 6 students in traditionally male courses" (NWLC, 2005, apud Lufkin, Wiberg, Jenkins, Berardi, Boyer, Ardley, \& Huss, 2007, p. 427). Em outros estados, segundo o estudo, repetem-se as estatísticas.

No Brasil, os dados são equivalentes (Brasil/Ministério da educação e Cultura (MEC)/Instituto Nacional de Estudos e Pesquisas Educacionais Anísio Teixeira (INEP), 2005). É possível perceber um número crescente de mulheres presentes em cursos profissionalizantes. A área cujo índice de matrícula possui o mais alto percentual de mulheres é a da saúde, fato observado em todas as regiões. E o menor percentual de matrícula de muIheres está na área de Indústria, fato que também se repete em todas as regiões. Na área de Química, o número de mulheres é levemente superior 
ao de homens, mas é preciso ressaltar que nessa área se inclui o curso de Química de Alimentos onde se vê normalmente uma imensa matrícula feminina. A área de Construção Civil ainda tem consideravelmente um número de homens maior do que o das mulheres, mas na região Sudeste essa diferença já é pequena. Embora a área de Informática não tenha essa ideia de força física, de desgaste corporal, ainda há forte a presença do contingente masculino.

Essas disparidades indicam "that these patterns are not the product of unfettered choice alone, but rather that discrimination and barriers are limiting young men's and women's opportunities to pursue careers that are nontraditional to their gender" (Lufkin et al, 2007, p. 429). Além disso, implicam disparidade na ocupação profissional a ser exercida. As razões vão desde as relações presentes no âmbito familiar até as discriminações sofridas durante a atuação no mercado de trabalho. Lógico que, nesse momento, quando falamos de escolhas não convencionais, não nos restringimos apenas às meninas que se inserem na física, por exemplo, mas também aos meninos que se inserem em enfermagem. Tanto estes quanto aquelas infringem o que é socialmente determinado. De acordo com National Centers for Career and Technical Education - NCCTE (2003), as razões para que eles não escolham as carreiras denominadas femininas nem elas às carreiras masculinizadas são:

(a) lack of early exposure to nontraditional occupations and role models; (b) student attitudes; (c) unsupportive career guidance practices and materials; (d) lack of encouragement to participate in math, science, and technology; (e) stereotyped instructional strategies and curriculum materials; ( $f$ ) a chilly school/ classroom climate that can result in student isolation; $(g)$ lack of self-efficacy; and (h) limited support services (apud Lufkin et al, 2007, p. 432).

Os pais e mães, muitas vezes, por desconhecimento ou por falta de interesse ou por conta de sua formação pouco apresentam aos filhos e filhas a diversidade de profissões. As escolas quando apresentam as profissões aos/as discentes, não raro, expõem as convencionais. Nos Institutos e nas Universidades, também não existe uma política que acompanhe e assista os alunos e alunas durante o curso. Também não há seminários ou palestras que tratem como comuns aos dois sexos as profissões mais extremas. Os alunos que gostam das disciplinas da área de exatas são vistos como 
"CDF", mas quando se trata de alunas a situação é pouco mais grave, pois são vistas como esquisitas.

Se restringirmos as causas quanto ao fato de as garotas não escolherem as carreiras técnicas/tecnológicas, boa parte das pesquisas apontam: a família que não a incentiva, a academia tem poucos modelos femininos 1 , não são dadas diversas informações acerca de determinadas profissões (Burger et al, 2007). Na escola, a falta de incentivo é enorme: "In general, "smart" and "popular" are not synonymous during adolescence, and physics, being the least "cool" and most "nerdy", is the hardest for girls to embrace" (Borg, Budil, Ducloy, \& Mckenna, 2005 apud Burger et al, 2007, p. 261).

\section{Sergipe}

Sobre "as juventudes sergipanas" constatou-se que tanto homens como mulheres pautam sua vida sobre "quatro pilares: família $(28 \%)$, emprego (24\%), estudos (16\%), saúde (12\%). Esses quatro assuntos abrangem $80 \%$ dos motivos de satisfação ou não Satisfação dos jovens em relação à vida" (Idem, p. 48). Em nossa pesquisa os/as estudantes situam-se numa classe social que vê o trabalho como parte de sua vida, como constituição de si, vê o salário como meio de sobrevivência, como o que lhe permite circular nos meios sociais e galgar status e reconhecimento. Para eles e elas, o trabalho é "um momento efetivo de colocação de finalidades humanas, dotado de intrínseca dimensão teleológica. $\mathrm{E}$, como tal, mostra-se uma experiência elementar da vida cotidiana, nas respostas que oferece aos carecimentos e necessidades sociais" (ANTUNES, 2000, p. 168). Não é em vão que se matriculam em uma escola profissionalizante. Os alunos e alunas expressam ao entrar na escola um desejo de se preparem, de se capacitarem para determinadas profissões, aumentar as suas habilidades e o nível educacional.

É o trabalho que os leva à escola e o que mais lhes preocupa gerando insatisfação com a vida. Pois é a partir de trabalho que pensam em casar-se, sustentar uma família, ou seja, "É preciso estudar, para ter um emprego. É preciso ter um emprego, para sustentar sua família. Esse é o raciocínio básico da maioria dos jovens sergipanos" (Idem, p. 63). Em relação ao gênero há pouca diferença entre rapazes e moças quanto à valoração do trabalho: 
"Os rapazes conferem mais importância ao emprego (25,8\% do conjunto de motivos, contra 22,9\% entre as moças)" (Idem, p. 63). Também, não se observou distinção quanto ao assunto do desemprego de longa duração.

A maior diferença é quanto a de possuir ou não possuir renda pessoal, o número de jovens mulheres que dizem não ter salário algum é claramente superior ao número dos rapazes: "As moças estão ainda mais pobres ou dependentes do que os rapazes. Além disso quando possuem renda pessoal, essa é menor do que a dos rapazes" (CHARLOT, 2006, p. 135). O desemprego não se deve à vocação de dona do lar (CHARLOT, 2006).

Referente à educação, há algumas diferenças: a) as mulheres passam mais tempo na escola enquanto os homens têm trajetória escolar com interrupções. Os motivos de desistência, tanto deles quanto delas, são vários, dentre os quais estão "oportunidade de trabalho (masc.: 41,8\%; fem.: 13,4\%); dificuldades financeiras (masc.: 12,8\%; fem.: 15,2\%) gravidez (masc.:0,2\% ; fem.: 21,2\%)" (CHARLOT, 2006, p. 63).

Referente ao IFS, apresentamos aqui os discursos percebidos em três dos GF realizados. Envolveram alunos e alunas do dos cursos de Eletrotécnica, de Eletrônica e Desenvolvimento de Sistemas. O primeiro deles - GF1 - continha três garotas e sete garotos cuja média de idade era 24 anos e cursavam o último período do técnico subsequente noturno; o segundo GF2 -, cinco garotos cuja média de idade era 18 anos e cursavam o quarto ano do técnico integrado matutino; o terceiro - GF3 -, seis garotas cuja média de idade era 17 anos e cursavam o terceiro ano do Integrado matutino.

\section{Formação acadêmico-profissional}

Todos os/as participantes do GF escolheram estudar no Instituto por, especialmente, duas razões: a promessa de conseguirem emprego após a formação e o fato de estudarem em uma instituição pública federal, consequentemente, a garantia de ter excelentes profissionais, laboratórios etc. Evidentemente que, ao longo dos anos, perceberam problemas.

As críticas e os elogios à escola se misturam. As críticas dizem respeito em grande parte à estrutura física e pedagógica. Quanto à primeira, 
reclamam e denunciam a falta de equipamentos e registram a existência de materiais envelhecidos que comprometem as experiências que realizam. Quanto à segunda, queixam-se da falta de algumas disciplinas julgadas fundamentais e dos professores não assíduos, descomprometidos e demasiadamente teóricos: "Aqui no Instituto, você vê que são professores graduados, capacitados, diferentes do que há nas outras escolas, têm muito conhecimento mas são relaxados, não vêm à aula" (Pedro - Eletrotécnica).

Além das queixas mencionadas, o GF 3 lamenta o fato de ficar muito tempo na escola e ao contrário de mencionar críticas a professores prefere falar de disciplinas como Física - considerada difícil pelas alunas de eletrotécnica e de eletrônica - e de Lógica - pelas alunas de Desenvolvimento de Sistemas. As dificuldades nas disciplinas e a falta de incentivo da escola são tantas que é o único focal em que participantes anunciam desejo de desistir da carreira.

Quanto ao relacionamento entre eles, o GF 1 não alegou problemas, mas a presença de colegas mulheres entre eles não passa despercebida: as meninas são as representantes de turma nas reuniões de Conselho do IFS tanto em Eletrotécnica como em Eletrônica. E na formação de equipes para trabalhos, elas costumam ser disputadas pois são mais organizadas e apresentam-se melhor: "Porque ela é a menina mais bonita da sala e o professor vai gostar" (Franklin - Eletrônica/subsequente).

O GF 2 em geral não reclama do fato de não terem meninas em sala de aula. Na verdade, no início em 2008, a turma era composta de trinta e oito alunos e duas alunas, hoje, no final, só há 14 homens. Apesar disso, todos são unânimes em afirmar que as mulheres são tão inteligentes quanto eles e podem sentir as mesmas dificuldades de aprendizagem. Quando se fala da desistência das duas meninas, imediatamente dois deles lembram que também houve muita desistência dos meninos. Entretanto, um aluno diz: "Ah, claro que senti falta das meninas, com mulher fica mais fácil de você criar relacionamentos." (Iury - Eletrotécnica). Outros ressaltaram que se houvesse a presença delas, possivelmente, teria afetado as conversas em sala de aula: "Uma coisa é a conversa só com homens, se tivesse tido mulheres teria sido muito diferente... a gente não teria falado tudo... ou criaríamos códigos ou elas colocariam um algodãozinho no ouvido" (Albert - 


\title{
Eletrotécnica).
}

Também quanto às "conversas", as meninas do GF 3 fizeram comentários:

\begin{abstract}
"Coisa insuportável é quando falam de futebol, eles repetem e começam a tirar onda um com outro e não falam de mais nada. Passam o dia assim." (Samira - eletrônica). "Um dia? Uma semana por vezes!... Acho que tem momentos que eles esquecem que somos meninas e ficam falando como se tivesse só homens." (Luana - Desenvolvimento de Sistemas)
\end{abstract}

E ao serem indagadas se elas os incomodam de algum modo, responderam: "Não há nada que possa constranger aqueles meninos!" (Gabi - Eletrotécnica).

\section{Expectativas de trabalho}

O GF 1 contém trabalhadores. Dos sete rapazes, cinco trabalhavam dos quais dois eram graduados e dois estavam cursando o superior na UFS; os dois demais estagiavam. As três meninas ainda não estagiavam nem trabalhavam, mas uma delas fazia também curso superior na UFS. Entre elas, uma de Eletrotécnica expressou sentir dificuldades com a aprendizagem, especialmente com as disciplinas de Eletricidade, ao passo que as outras duas, uma de Eletrotécnica e outra de Eletrônica eram reconhecidas pelos seus pares como "CDF". Homens e mulheres dizem que as chances de conseguirem emprego são bem maiores com o certificado de técnicos. Todos acreditam ser ou se tornar excelentes técnicos, mas lamentam que o mercado explore bastante.

O GF 2 foi o mais otimista. Os cinco alunos estão no estágio, um estagia no próprio IFS e os outros em uma renomada empresa de energia. Estes, inclusive, receberam proposta de trabalho. Todos creem que serão aprovados no vestibular, apenas um garoto não prestou vestibular pois não tem certeza se seguirá carreira. Relataram ser uma turma das mais promissoras do Instituto nos últimos anos. Eles não temem desemprego: "Que casa não vai precisar de instalação elétrica?" (Albert - Eletrotécnica) ou "O país só cresce a economia se ele tiver energia" (Igor - Eletrotécnica).

O GF 3 foi o mais comedido. Nenhuma das três alunas de eletrotécnica estagia, nem trabalha nem quer continuar a carreira. Em Desenvolvimento 
de Sistemas, das duas participantes, uma abandonará e a outra, que já estagiou, agora é contratada pela empresa e prosseguirá na carreira. A de eletrônica está bem no curso, está convicta de que no próximo ano estagiará em uma grande empresa e prestará vestibular para um curso similar ao seu.

Em todos os três GF, ficou dito que as mulheres têm mais dificuldade em arranjar estágio e emprego, relataram ter visto cartazes no mural do IFS a solicitarem estudantes para estágio explicitando o sexo, no caso o masculino. Apesar disso, No GF 3 uma aluna de informática e outra de eletrônica não receiam a seleção e acreditam ser muito importante que as mulheres sigam em frente. As demais reconhecem as dificuldades para inserir-se na carreira, mas não é isto que as afugenta: foi o curso em si, com suas disciplinas, seus laboratórios mal equipados e, possivelmente, um erro na escolha que fizeram.

No GF 1, houve bastante polêmica ao terem de considerar que todas as profissões servem às mulheres. Houve entre eles, quem alegasse riscos para a mulher - assédio - e riscos para a empresa - menos rendimento.

Eis uma sequência de diálogo entre alunos/as de Eletrônica Subsequente:

"Trabalhei em uma fábrica que tinha poucas mulheres, eram
assediadas, se sentiam mal" (Rodrigo). "Existem riscos de
acontecer alguma coisa desagradável na empresa" (Luan).
"Sempre tem um pervertido. (Adriano). "Atrapalhar o rendi-
mento do pessoal" (Vitor). "Ficar 15 dias em uma plataforma
com uma mulher?" (Cristiano). "Qual o problema?" (Marilia).
"Se a mulher se impor e se der o respeito e não der nenhuma
entrada" (Michele). "Uma coisa é você impor respeito e outra
é o homem não respeitar!" (Vitor). "Então não é profissional!"
(Denilson).

Houve questionamentos a certos comportamentos relacionados a modelos femininos:

sempre tive uma dúvida em relação às mulheres, sempre são muito sentimentais e eu gostaria de saber se realmente algumas profissões isso não afeta, tipo, a mulher no exército fica com aquele sentimentalismo, não vai atrapalhar ela? (Elcris Eletrônica).

Mas houve também ideias que expressavam mudanças nas ações e nas posturas das mulheres: "As mulheres não acreditavam em si mesmas. (...) com essa evolução no mundo todo, acho que botaram na cabeça que 
conseguem fazer qualquer coisa, qualquer trabalho, não há mais limites!" (Denilson - Eletrônica).

Inevitavelmente, surgiram os aspectos biológicos: gravidez e menstruação. Esses aspectos são vistos pelos rapazes como empecilhos para que as fábricas as contratem, eles constatam que nas empresas onde trabalham ou estagiam sempre dão preferência a mulheres solteiras em virtude de tais situações: "Geralmente a empresa prefere o homem, a mulher tem que ser solteira, sem filhos. É difícil fazer a entrevista e perguntar ao homem: você tem filho? mas a mulher é assim mais do lar" Cristiano - Eletrotécnica/subsequente).

Também reconhecem que as maiores dificuldades são impostas pelos interesses econômicos: "o problema maior para as empresas é terem de dar 06 meses de licença maternidade, como nós vivemos num mundo capitalista ninguém quer perder, a empresa não quer esperar." (lury - Eletrotécnica). As mulheres rebatem os argumentos: "Acho que não, ora gravidez, menstruação, toma-se remédio e TPM é bobagem, tem dia que a gente acorda e não tá bem mesmo. Os homens também acordam em dias que eles não tão bem, todo mundo tem seu dia em que não tá bem" (Mônica - Desenvolvimento de Sistemas).

\section{Considerações Finais}

Por ora, foi possível constatar que o momento é de experimentar novas realidades, novas posições. Os rapazes demonstram certo desconhecimento do corpo feminino e explicitam em suas falas muito do senso comum. Os mais novos apostam em mais mudanças e parecem encarar com mais abertura o fato de elas estarem com eles no mesmo ambiente de trabalho. Os mais velhos parecem perceber melhor a dureza do mercado de trabalho e explicitam o que já vivenciam. Quanto às mulheres, há nítida ambiguidade, algumas se mostram mais otimistas e confiantes, sentem-se bem no curso que escolheram, cientes das dificuldades mas crentes que as superarão. Outras desistem. As meninas do GF 3 mais entusiastas com o curso relataram receber apoio de seus pais e de professores, as menos entusiastas relataram ter se matriculado por conta dos pais e de não ter abandonado 
o curso por conta deles também. Entretanto, o dia a dia do curso, as disciplinas, os colegas, os laboratórios fizeram-lhes mudar de ideia: uma quer ir para medicina, outra para a administração de negócios e as outras duas ainda não sabem que outro curso farão quando concluírem o Ensino Integrado.

Se focarmos a comparação entre os GF 2 e GF 3, não deve ser coincidência que somente naquele todos estagiem e creiam em trabalho tão logo concluam o curso, mais que isto, preparam-se para concursos públicos. Ora, considerando que por serem alunos/as do Integrado, passam 4 anos na escola, não teria a instituição responsabilidades no sucesso de uns e no abandono de outros? Possivelmente, muitos preconceitos relacionados a gênero passam despercebidos na escola e na empresa, mas talvez seja na escola em que se deva primeiro perceber as artimanhas de exclusão e lutar contra elas.

\section{Referências Bibliográficas}

ANTUNES, R. (1999). Os Sentidos do Trabalho: Ensaio sobre a Afirmação e a Negação do Trabalho, Ed. Boitempo, São Paulo.

BRASIL, MEC/INEP. (2005). Trajetória da mulher na educação brasileira: 1996-2003. In T. Godinho, D. Ristoff, A. Fontes, I. de M. Xavier e C. E. M. Sampaio (Orgs.) 109 p.

BURGER, C., ABBOTT, G., TOBIAS, S., KOCH, J., VOGT, C., SOSA T., BIEVENUE, L., CARLITO, D., \& STRAWN, C. (2007). Gender equity in science, engineers, and technology. In Klein, S. S., Richardson, B., Richardson, D., Grayson, D. A, Fox, L. H., Kramarae, C., Pollard, D. S., Dwyer, C. A. (Orgs.). Handbook for Achieving gender equity through education. Routledge (pp. 255-279) Taylor, \& Francis Group New York, London.

BUTLER, J. (2003). Problemas de Gênero: Feminismo e Subversão da Identidade. Trad. Renato Aguiar. Rio de Janeiro: Civilização Brasileira.

CARVALHO, M. E. (2007, setembro). Gênero, Educação e Ciência. Conferência de Encerramento do I seminário Gênero e Práticas Culturais, João Pessoa.

CHARLOT, B. (2006). Juventudes sergipanas: relatório de pesquisa. 
UNESCO : Governo de Sergipe, Secretaria do Combate à Pobreza e da Assistência Social, Aracaju.

DEMO, P. Educação profissional, vida produtiva e cidadania. Senac. Recuperado em 29 de setembro de 2008 de http//:www.senac.br/informativo/ BTS/241/boltec241a.htm.

GARCIA, N. M. D. e FILHO, D. L. L. (2010). Politecnia ou Educação Tecnológica: desafios ao ensino médio e à educação profissional. In N. D. Garcia e D. L. L. Filho (Orgs.) Trabalho, educação e Tecnologia: alguns dos seus enlaces, Curitiba- PR: editora UTFPR, pp. 21 - 55.

LUFKIN, M., WIBERG, M., JENKINS, C., BERARDI, S., BOYER, T., ARDLEY, E., HUSS, J. (2007). Gender equity in career and tcchnical education. In: In Klein, S. S., Richardson, B., Richardson, D., Grayson, D. A, Fox, L. H., Kramarae, C., Pollard, D. S., Dwyer, C. A. (Orgs.). Handbook for Achieving gender equity through education. Routledge Taylor \& Francis Group New York, London.

MTE/RAIS. (2010). Características do Emprego Formal segundo a Relação Anual de Informações Sociais - 2010. Recuperado em 20 de abril de 2011 de http://www.mte.gov.br/rais/2010/arquivos/Resultados_Definitivos.pdf.

SCOTT, J. W. (1989). Gênero: uma categoria útil de análise histórica. In: Educação e Realidade, Porto alegre, 16(2): jul-dez.

WEINER, G. (2010). Género y educación en Europa: revisión de la literatura. In EACEA- Eurydice. Diferencias de género en los resultados educativos: medidas adoptadas y situación actual en Europa. Bruselas: Eurydice, p. 142. 